\section{Construções Residenciais PÚBLICAS EM ROMA NO SEGUNDO PÓS-GUERRA: O BAIRRO INCIS EM DECIMA}

\section{Alessandra Cerroti}

Tradução: Beatriz Mugayar Kühl

A construção do bairro de Decima enquadra-se na atividade mais ampla do INCIS (Istituto Nazionale per le Case degli Impiegati dello Stato - Instituto Nacional para Residências dos Funcionários Públicos), criado pelo Decreto Régio n. 1.165 de 28 I94 de abril de 1939, com a função de oferecer, aos empregados civis e militares do Estado, habitação em edifícios residenciais públicos com condições favoráveis.

A compreensão dessa arquitetura está diretamente ligada ao entendimento do relevante papel que as construções populares possuem no contexto histórico e social do pós-guerra: elas fazem as vezes, no modelo de desenvolvimento que então prevalece, de elementos de reabsorção e de reconversão da mão-de-obra não-qualificada de migração recente, proveniente do setor primário. A tendência de manter uma dimensão artesanal, com uso esporádico da pré-fabricação, em contraposição aos casos norte-europeus, por exemplo, recai no objetivo social, ligado à "necessidade habitacional", de empregar a maior quantidade possível de mãode-obra pouco qualificada.

Contemporaneamente, desenvolve-se a pesquisa, em âmbito urbano, de uma nova dimensão para o edifício, não apenas física, mas sobretudo organizacional, que se exprime na tentativa de superar os limites impostos pelas dimensões dos lotes e dos blocos habitacionais.

Claro está, pois, que o estudo dos modelos figurativos não pode ser feito sem levar em conta as tipologias de implantação e os sistemas construtivos; além dos aspectos mais propriamente expressivos, aqueles planimétricos se mostram de grande importância porque por meio deles transparecem, com freqüência, as escolhas dos projetistas relacionadas à relação com a cidade e o ambiente construído circunstante.

$\mathrm{Na}$ experiência italiana das construções populares nota-se, ademais, uma substancial persistência dos sistemas construtivos: com efeito, a alvenaria é dominante, realizada inicialmente como verdadeira alvenaria portante e, depois, como vedação de um sistema estrutural de concreto armado, constituindo, por substancial continuidade, um parêntese em relação aos sistemas pré-fabricados de importação. Essa considerável continuidade construtiva ocorre porque até mesmo a introdução da ossatura de concreto armado não distancia os projetistas do sistema de alvenaria portante, pois os elementos portantes se integram com a vedação, resultando em superfícies contínuas; desse modo, a potencialidade do concreto armado de liberar a fachada quase nunca é explorada.

No âmbito das construções residenciais públicas do segundo pós-guerra, verificam-se duas linhas principais de desenvolvimento dos modelos figurativos: de um lado, um primeiro grupo de realizações em que se exprime a ligação com o modelo racionalista, caracterizado por uma arquitetura composta de elementos estereométricos elementares; por outro lado, um segundo grupo chamado "neo-realista", no qual confluem reverberações de matriz organicista e a importância dada à valorização das especificidades italianas. As realizações das quais nos ocuparemos fazem parte desse segundo caso, mesmo se, comparadas com aquelas construídas por meio do programa INA Casa (Istituto Nazionale Assicurazioni - Instituto Nacional de Seguros) ${ }^{1}$, as obras arquitetônicas do INCIS apresentam características projetuais mais amadurecidas do ponto de vista formal, provavelmente por causa dos destinatários, diferentes, constituídos por uma classe social pequeno-burguesa. Com efeito, os êxitos arquitetônicos, apesar de terem a mesma atenção com os aspectos de composição do ambiente, são diversos, mais atentos ao emprego dos materiais e às soluções tecnológicas dos detalhes construtivos.

O bairro de Decima deve seu projeto urbanístico inteiramente a Luigi Moretti, um dos arquitetos mais prolíficos e significativos do século 20 na Itália, enquanto o projeto arquitetônico, além do próprio Moretti, é obra também de Adalberto 


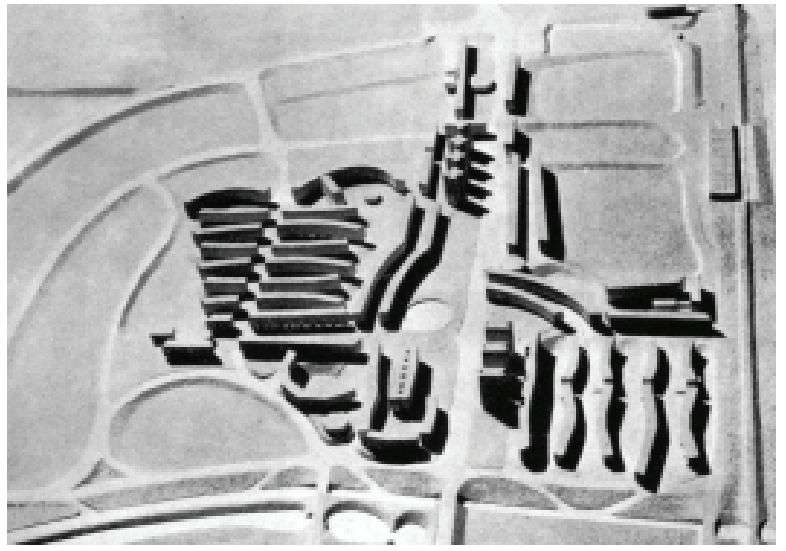

Figura 11: Maquete volumétrica do conjunto do bairro Decima. Os edifícios alinhados à esquerda pertencem à segunda fase de construções

Fonte: MORETTI, L. II quartiere INCIS a Roma nella zona a sus dell'Eur. Informatigioni urbanistiche, Roma, n. 1, p. 27-29, 1961
Libera, Vittorio Cafiero, Ignazio Guidi e de seus numerosos colaboradores.

O primeiro núcleo de edifícios foi realizado de 1961 a 1965, mas o bairro foi completado a seguir, por sucessivas intervenções que se estenderam até 0 final dos anos 70 (Figuras 11 a 14). A superfície prevista para o complexo era de $154 \mathrm{mil} \mathrm{m}^{2}$, dos quais 29 mil ocupados pelas construções, 50 mil por vias, praças e estacionamentos, 5 mil por espaços destinados às crianças, 66 mil pelos jardins e 4 mil pelo complexo escolar.

Para situar o conjunto no novo plano diretor, aprovado em 1962, a área em que surge Decima, na zona sul de Roma, nas proximidades do EUR ${ }^{2}$, foi caracterizada como um segundo pólo ao sul da

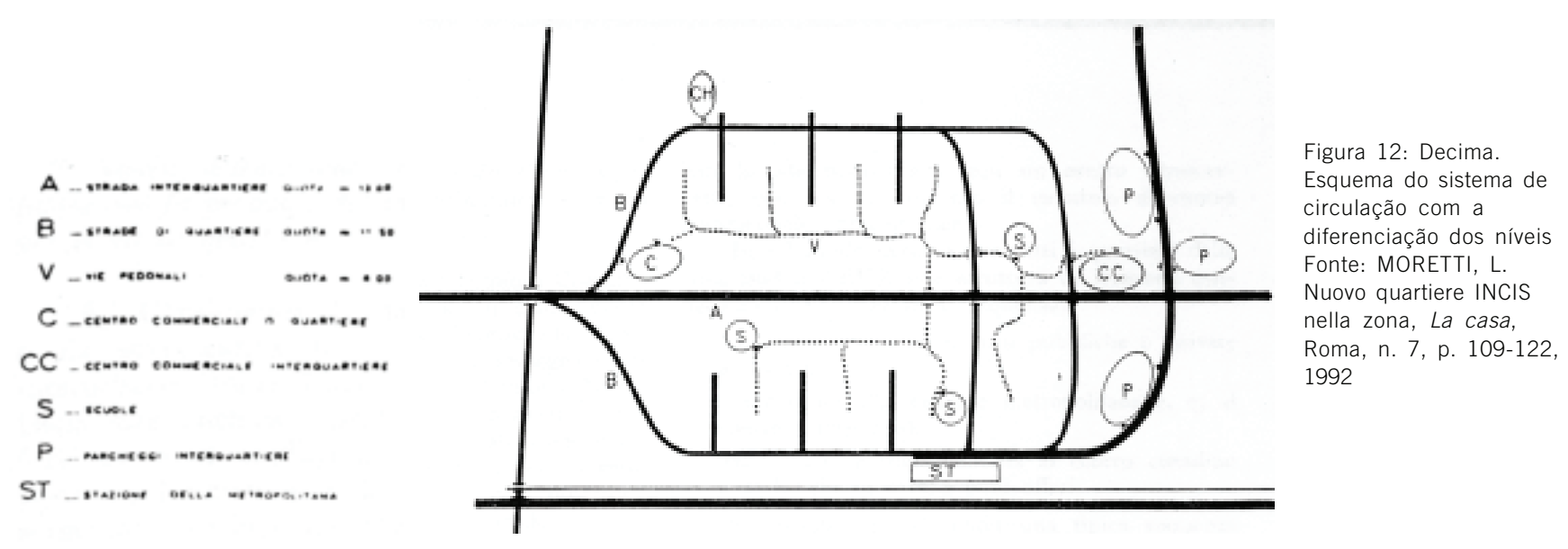

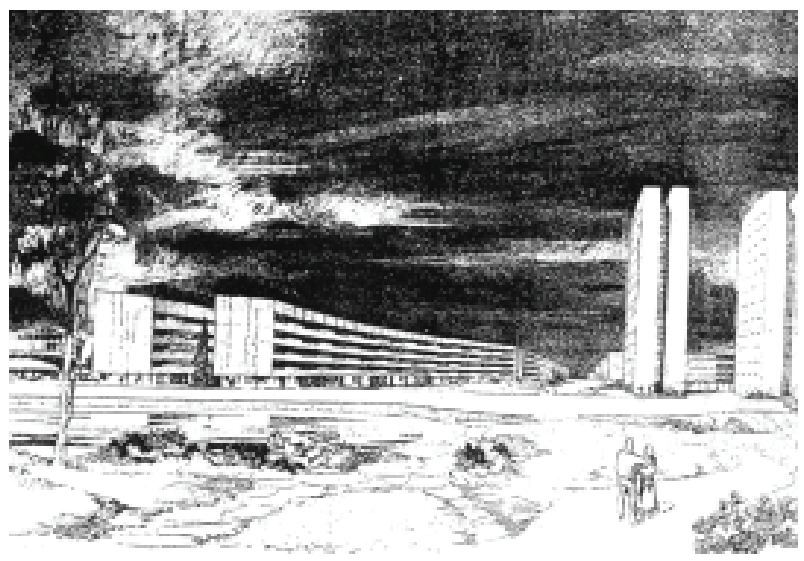

Figura 13: Decima. Perspectiva do projeto Fonte: Idem Figura 12

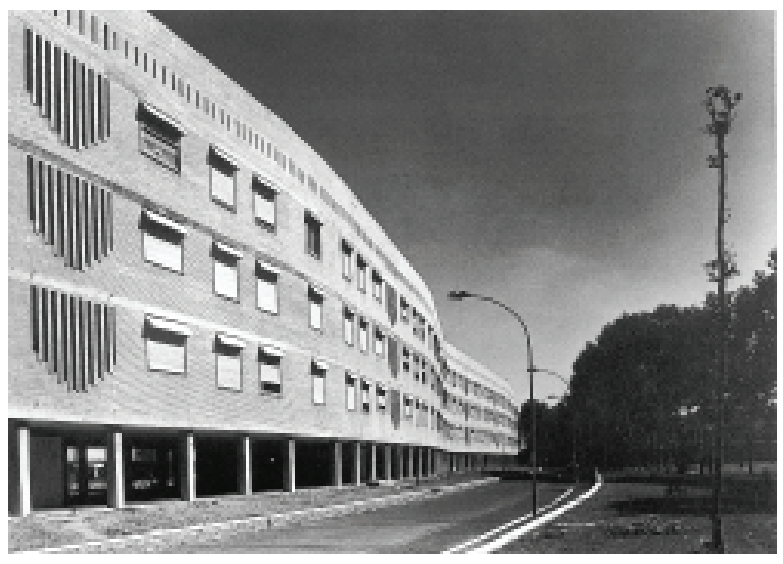

Figura 14: Decima. Foto da época da conclusão das obras Fonte: BUCCI, F.; MULAZZANI, M. Luigi Moretti. Opere e Scritti. Milão: Electa, 2000 
Figura 15: Foto da Vila Olímpica no início dos anos 60

Fonte: GERMANI, R. Edilizia Popare, Roma, n. 35, p. 27-30, 1960

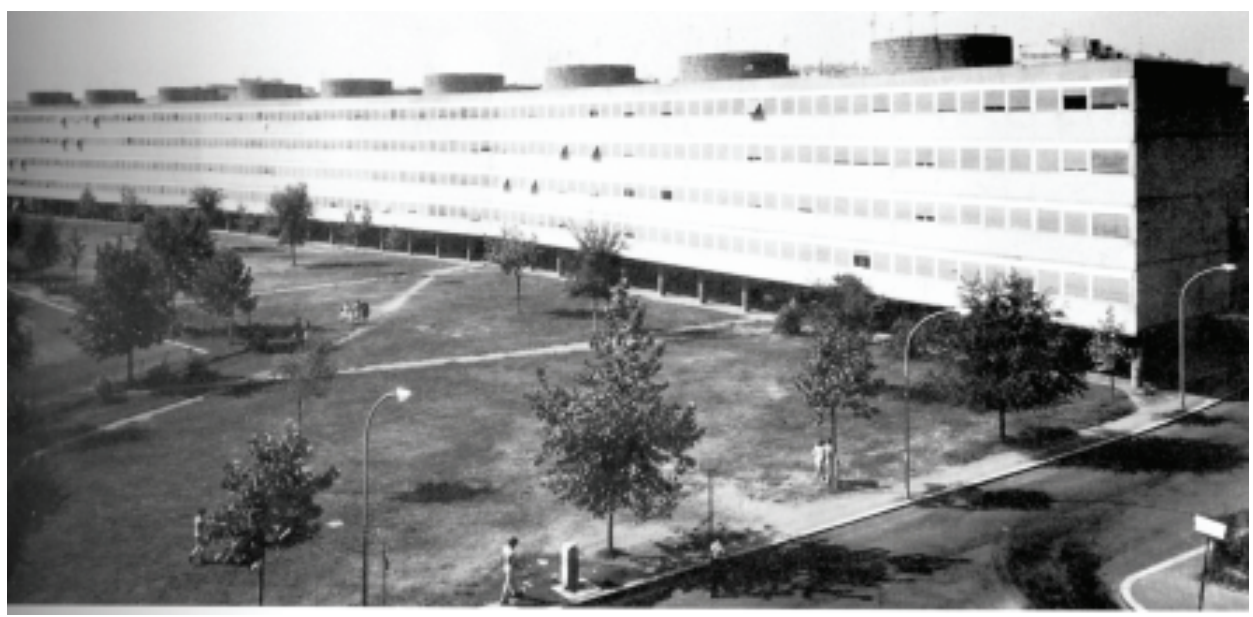

cidade (o primeiro é a Vila Olímpica, no norte, o qual já havia sido realizado), representando, ainda uma vez, uma repercussão do sistema de expansão em direção ao mar, proposto pelo regime fascista.

O bairro de Decima foi, desse modo, estudado e depreendido com relação ao seu gêmeo, a Vila Olímpica (Figura 15), realizada para os atletas dos Jogos Olímpicos de Roma de 1960 e depois destinada a funcionários públicos. Apresentando características tipológicas e de implantação similares, a Vila Olímpica segue a diretriz Olímpica, cujo projeto de expansão será a via interbairros, com função de baricentro, equilibrada por Decima.

A continuidade de intenções, em relação ao town design italiano, foi superada em Decima por uma maior maturidade e completude da expressão global. Os dois bairros nascem, de todo modo, ligados por uma visão unitária do desenvolvimento da cidade: em ambos a vinculação com as experiências norte-européias contemporâneas parece mais forte e completa (aspectos sociais da "vizinhança", subdivisão dos percursos de pedestres e de carros com níveis diferenciados, função projetual dos espaços verdes como áreas de conexão) do que nos exemplos coevos italianos, realizados desde 0 primeiro pós-guerra, como o já mencionado programa INA Casa.

Um aspecto de grande interesse é a atenção projetual dada à subdivisão hierárquica das vias, seja naquilo que concerne aos percursos de ligação do conjunto com o próprio centro, seja entre o conjunto e a cidade. A estruturação do sistema viário, realizada apenas de modo parcial, comportava a separação em três cotas distintas: circulação veloz, tráfego local e percursos de pedestres.

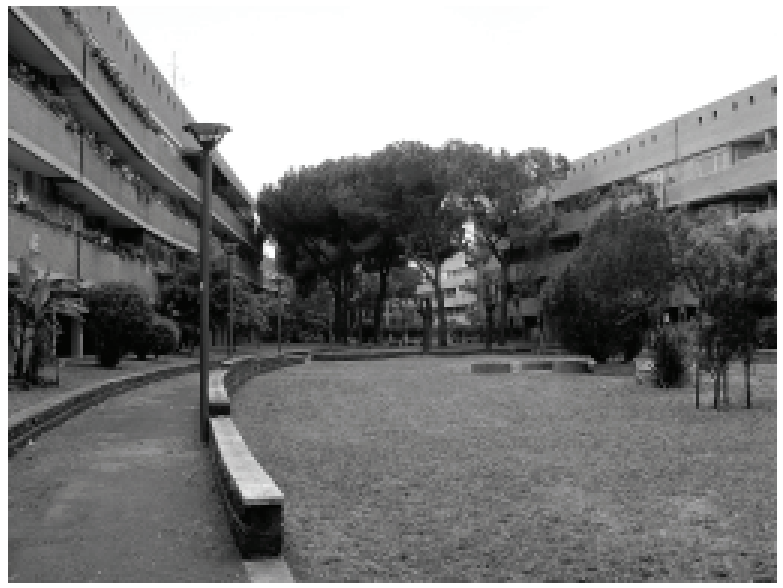

Figura 16: Decima. Uma típica "valeira" destinada a jogos e à recreação

Crédito: Foto de Alessandra Cerroti

O bairro é articulado em núcleos urbanos autosuficientes de 600 a 1.000 habitantes, articulados em torno de espaços verdes e vias de pedestres. A idéia de vizinhança é desenvolvida com a criação de "valeiras" que conferem movimento à composição, graças a contínuas mudanças das visuais (Figura 16).

Até mesmo a escolha da tipologia das edificações - com forte componente horizontal, limitada altura e, sobretudo, a articulação, segundo perspectivas precisas, dos corpos construídos transmite o senso de escala e de dimensão. A linguagem arquitetônica - em que os pilotis e, em alguns casos, as janelas, desenvolvendo-se em faixas estreitas e contínuas em toda a fachada, constituem os temas dominantes - é uma proposta de reelaboração das poéticas racionalistas, viés, até aquele momento, pouco explorado na arquitetura italiana. 


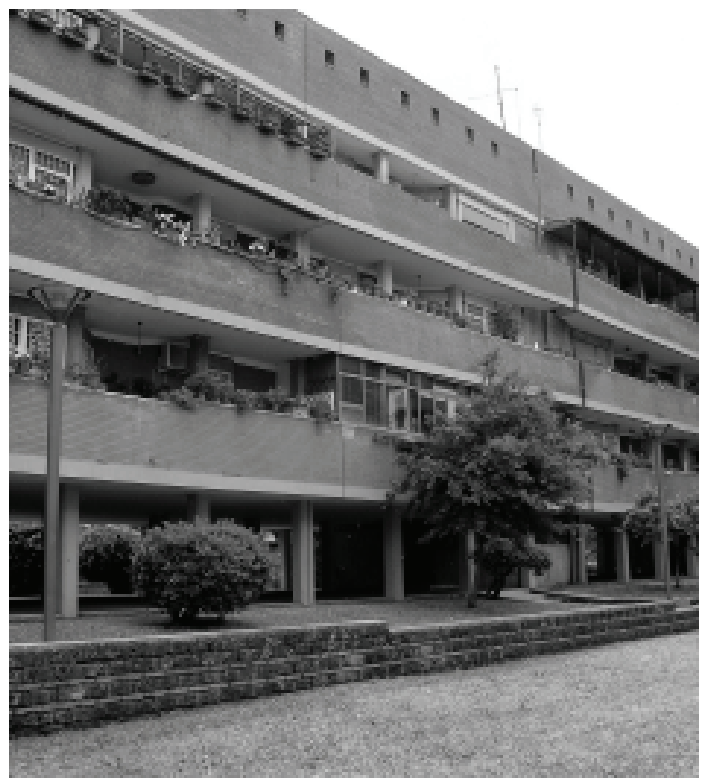

Figura 17: Decima. Com o decorrer do tempo, verificou-se um fechamento, total ou parcial, das aberturas, com a intenção de aumentar a área habitável: esses acréscimos, todos diversos, sem nenhum critério comum, alteraram fortemente o aspecto dos edifícios e da composição unitária do bairro

Crédito: Foto de Alessandra Cerroti

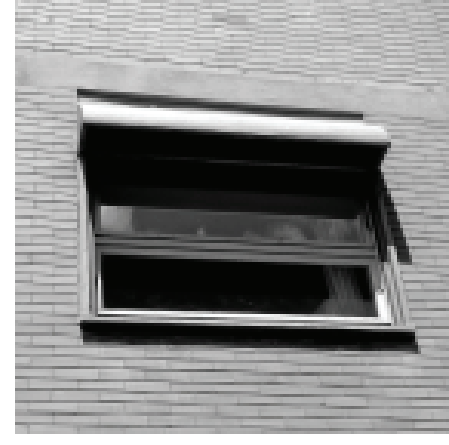

Figura 18: Decima. Pormenor de uma janela, em que se nota a grande atenção dada aos detalhes construtivos: os caixilhos foram freqüentemente substituídos, mesmo, como é possível observar na foto, ainda presentes elementos originais em condições razoáveis de conservação

Crédito: Foto de Alessandra Cerroti

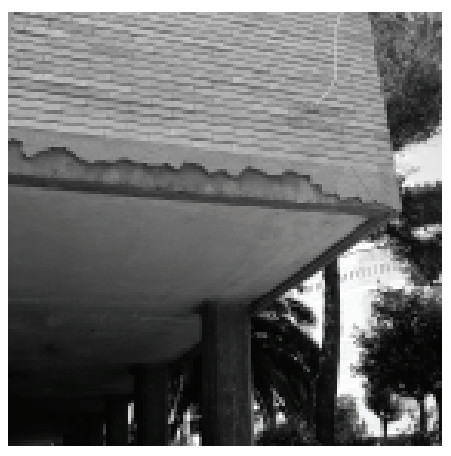

Figura 19: Decima. A degradação se manifestou, principalmente, onde a própria conformação do edifício continha elementos mais expostos à agressão dos agentes atmosféricos Crédito: Foto de Alessandra Cerroti
O caráter urbano unitário e a qualidade arquitetônica do núcleo, derivados das equilibradas relações entre elementos naturais e construídos, são de grande interesse por seus atributos residenciais e valores formais.

A qualidade arquitetônica do conjunto habitacional é alcançada pela justaposição de elementos similares e formas reproduzíveis, sem, contudo, incorrer no risco da repetitividade: com efeito, a relação entre elementos construídos, espaços públicos e áreas verdes é dinâmica e as visuais, sempre diversas, por causa das formas arquitetônicas côncavas e convexas, fazem com que a composição do conjunto não seja, de modo algum, monótona.

Por muitos anos, a sinergia entre os poucos recursos disponíveis e a conseqüente carência de manutenção resultou na degradação dos edifícios e dos outros elementos que compõem o conjunto (Figuras 17 a 19). A suscetibilidade à deterioração é muito comum na arquitetura contemporânea, sobretudo quando se apresentam casos de experimentação construtiva: a fragilidade é, com freqüência, devida à adoção de soluções arquitetônicas inovadoras, mas também ao emprego 
de técnicas construtivas não ainda suficientemente testadas.

Mesmo que o conhecimento dos numerosíssimos materiais da época seja um pressuposto para qualquer intervenção, nota-se, em geral, pouca atenção pela materialidade da obra, algo com repercussão negativa nas fases operacionais.

Apresenta-se, pois, a questão, sempre mais urgente, de como conservar e intervir nesse patrimônio arquitetônico recente. Em particular, sua complexidade não admite escolhas de intervenção simples (demolir, conservar, construir ex novo), sem avaliações adequadas. Pode-se considerar esse patrimônio do ponto de vista do uso, em termos de desempenho, sob a ótica cultural, simbólica, memorial, como documentos históricos, mas apenas depois de análise acurada desses valores é possível determinar o tipo de intervenção, do mais radical ao mais conservativo, e as modalidades de execução.

Decima é um exemplo de grande êxito formal que se configura, essencialmente, em virtude das relações entre os componentes de sua estrutura. Por isso, essa complexa trama de relações não pode ser modificada com substituições arbitrárias, remoções ou acréscimos, sem lesar o organismo arquitetônico, urbano e territorial. Sob esse prisma, os aspectos que tornam esses conjuntos partes da cidade e estruturam a forma urbana são elementos expressivos para a avaliação dessas obras e para a fase operacional da intervenção. Ademais, sua importância testemunhal é significativa, pois, mesmo não sendo obras explicitamente "artísticas", possuem uma conformação; sua apreciação estética é importante, mas não pode ser equiparada com uma avaliação integral, pois devem ser consideradas também as componentes funcionais.

Torna-se, então, um momento essencial, na abordagem desse tipo de construção de valor histórico, a identificação dos elementos nevrálgicos da qual depende o valor testemunhal do conjunto e dos edifícios singulares, tanto na obra de "autor" como nas obras correntes: os valores para a composição do ambiente e do contexto. Tal abordagem deve ser aprofundada em escalas cada vez mais precisas: daquela do bairro, relativa à morfologia urbana, àquela do edifício, relacionada à tipologia das edificações, até se chegar aos pormenores construtivos. À luz dessas premissas, é necessário ter grande cuidado e atenção na escolha do tipo de intervenção, fase sucessiva e diretamente relacionada ao reconhecimento de valor (arquitetônico, urbano, etc.), diferenciando inequivocamente os termos, freqüentemente usados de modo abusivo, de recuperação e restauração; a falta de compreensão em relação a eles resulta em conseqüências dramáticas no campo operacional. Ambos se relacionam a intervenções em preexistências a serem conservadas, valorizadas, reestruturadas, ou restauradas, dependendo do caso. A recuperação é voltada, porém, para a reaquisição de um bem com escopos econômicos e sociais, como reativação de uma fonte, na qual o aspecto funcional prevalece sobre o conservativo; o restauro, ao contrário, mesmo considerando a função um elemento qualificador da intervenção, parte de finalidades culturais e memoriais.

Por meio de uma avaliação abrangente das intervenções já realizadas, em âmbito operacional, "distinguem-se duas correntes principais: para as obras de valor reconhecido, ademais pertencentes à produção arquitetônica da primeira metade do século XX, nota-se uma difusa tendência para a 'repristinação ao idêntico'; para as construções mais recentes, do segundo pós-guerra em diante, são muito comuns as intervenções de contínua e desenvolta substituição. No geral, portanto [...], continua-se a refazer, e não a conservar[...]"3.

Seria estimulante, portanto, verificar em campo, caso a caso, as modalidades de aplicação dos princípios basilares do restauro para esses casos de construções residenciais públicas do segundo pósguerra. O objetivo, para conservar e tutelar esse precioso patrimônio histórico e arquitetônico, é aquele de tentar alcançar a contemporização entre conservar e inovar na dinâmica urbana, levando-se em conta os valores arquitetônicos e de composição do ambiente.

Para concluir com as palavras de Giovanni Carbonara, é necessário "substituir o círculo vicioso construção-degradação-demolição, pelo círculo virtuoso construção-reconhecimento-manutençãoconservação-restauro" 4 .

\section{Bibliografia}

BONELLI, R. Moretti. Roma: [s. n.], 1975.

BUCCI, F.; MULAZZANI, M. Luigi Moretti. Opere e scritti. Milão: Electa, 2000. 
CARBONARA, Giovanni. Avvicinamento al restauro. Nápoles: Liguori, 1997.

FABIANI, R. Decima: Quartiere sereno. Capitolium, Roma, n. 1, p. 40-46, 1966.

FINELLI, L. Luigi Moretti. La promessa e il debito. Roma: Officina, 1989

MORETTI, L. II quartiere INCIS a Roma nella zona a sud dell'Eur. Informazioni urbanistiche, Roma, n. 1, p. 27-29, 1961.

_. Nuovo quartiere INCIS nella zona EUR. La casa, n. 7, p. 109-122, 1962.

RossI, P. O. Roma. Guida all'architettura moderna 1909-2000. Bari: Laterza, 2000.

SALVO, Simona. Problematiche e specificità del restauro dell'architettura moderna e contemporanea. In: PALMERIO G. (Org.). Appunti di restauro. Roma: Palombi, 2005.

PALMERIO G. (Org.) Appunti di restauro. Roma: Palombi, 2005.

PALMERIO P. II quartiere di Decima: Valori architettonici e ipotesi di restauro. In: CASSETTI, R.; SPAGNESI, G. (Org.) Roma contemporanea. Roma: Gangemi, 2006.

SANTUCCIO, S. Luigi Moretti. Roma: Zanichelli, 1986.

SPAGNESI, G. Quartiere Incis a Decima (Roma). Rassegna dell'edilizia, Roma, n. 6, p. 6-15, 1966.

UN NUOVO quartiere dell'Istituto Nazionale Case Impiegati dello Stato (INCIS) inaugurato a Roma in via di Decima. Edilizia Popolare, Roma, n. 67, p. 13-18, 1965.

\section{Notas}

(1) Em fevereiro de 1949, Amintore Fanfani, ministro do Trabalho e da Previdência Social do governo De Gasperi, apresenta a Lei n. 43, "Providências para aumentar o emprego de mão-de-obra, promovendo a construção de casas para trabalhadores". A lei dá origem ao plano INA Casa: o plano, com duração de sete anos, depois prorrogado por outros sete, tinha uma dúplice finalidade: realizar novas casas (atividade central da reconstrução) e enfrentar o problema político mais urgente, o desemprego. O órgão operacional é o INA Casa (criado no interior do INA - Instituto Nacional de Seguros - mas com uma certa autonomia), composto de dois corpos fundamentais: o Comitê Operacional (administrativo) e a Gestão INA Casa (aspectos técnicos e projetuais).

(2) Bairro originalmente criado para a Exposição Universal de Roma (EUR), prevista para 1942. A sistematização do sítio foi iniciada em 1937, mas as obras foram interrompidas com a guerra e retomadas em 1945 (nota da tradutora).

(3) SALVO, Simona. Problematiche e specificità del restauro dell'architettura moderna e contemporanea. In: PALMERIO G. (Org.). Appunti di restauro. Roma: Palombi, 2005.

(4) CARBONARA, Giovanni. Avvicinamento al restauro. Nápoles: Liguori, 1997.

\section{Alessandra Cerroti}

Arquiteta com especialização em Restauro de Monumentos pela Università degli Studi di Roma "La Sapienza". Atualmente desenvolve doutorado, desde 2006, em História e Restauro de Arquitetura na mesma universidade.

\section{A INTERVENÇÃO NA ARQUITETURA CONTEMPORÂNEA COMO TEMA EMERGENTE DO RESTAURO}

\section{Simona Salvo}

Tradução: Beatriz Mugayar Kühl

Desde a explosão da "emergência do moderno", há duas décadas, as coordenadas principais para a abordagem das intervenções na arquitetura contemporânea parecem não ter mudado: à parte um desenvolvimento hipertrófico da questão, agora um argumento "de ponta" do restauro, a propensão inicial a refazer, reconstruir, repristinar - excetuando-se algumas reconsiderações isoladas - radicou-se e consolidou-se.

Fenômeno internacionalmente difundido, a arquitetura do século 20 é objeto de ambições e interesses de natureza variada que dificultam sua correta recepção cultural, em especial por duas razões: o peso dado a seu valor de uso para finalidades práticas e econômicas e a aglutinação, a seu redor, de valores simbólicos, estreitamente relacionados à atualidade que, por um autodenominado "imperativo da conservação", obliteram seus conteúdos históricos e testemunhais. Em ambos os casos, a urgência a qual se impõe é aquela de "refazer para conservar", algo a acompanhar uma impulsiva projeção de instâncias fortuitas sobre a arquitetura contemporânea, tanto de natureza estética e histórica quanto econômica, ideológica, política ou social.

A tendência a afastar o tema do campo da restauração - algo possível de ser notado pelo variado léxico que até agora tem acompanhado a questão (restauro do moderno, do novo, do século 20, da arquitetura recente, etc.) comportou, porém, uma regressão à idéia, superada há um século, de dever-se salvar a imagem e não a consistência material de um testemunho, abrindo caminho para um ulterior 